\title{
Numerical Simulation of Two-dimensional Chloride Diffusion Meso of Recycled Concrete
}

\author{
Guangxu Lu, Lingqiang Yang* and Baoku Jiang \\ School of Civil Engineering and Architecture, University of Jinan 250022, China \\ ${ }^{*}$ Corresponding author
}

\begin{abstract}
It establishes the numerical simulation method of $\mathrm{Cl}^{-}$concentration distribution by using differential equation of similarity of two-dimensional heat conduction theory and twodimensional $\mathrm{Cl}^{-}$diffusion theory. Random aggregate model of Recycled concrete mesostructure is set up in the first place, then, the simulation is carried out on $\mathrm{Cl}^{-}$concentration distribution by using ANSYS software. The results obtained from the numerical simulation indicate that the distribution of chloride concentration is non-uniform within the recycled aggregate concrete, and the chloride concentration declines in waves along the diffusion depth; The chloride concentration in the recycled aggregate concrete shows the tendency of increase along with the increase of the content of recycled brick, the content of recycled aggregate, age as well as the diffusivity of the old interfacial transition zones, in other words, the durability of the recycled aggregate concrete becomes worse and worse.
\end{abstract}

Keywords-recycled aggregate concrete; random aggregate model; $\mathrm{Cl}^{-}$diffusion; brick content; numerical simulation

\section{INTRODUCTION}

Recycled concrete with different microstructure with ordinary concrete, the existence of the recycled aggregate and some of the blocks, make the recycled concrete porosity increased. it has an effect on the diffusion properties of internal chlorine ions[1]. The transport mechanism of chloride ion in recycled concrete is very complicated, mainly including diffusion, capillary action, osmosis and electrochemical migration[2], but the diffusion is considered to be the main mode of chloride ion transmission.

At present, in the study of the distribution of chloride ion concentration in concrete, many scholars have proposed various modification models based on the Fick diffusion law; Maage et al[3].based on a large number of experimental data, showed the chloride diffusion model in concrete with the change of chlorine ion diffusion coefficient over time; Chee et al[4] established a numerical model that can comprehensively consider the influence of chlorine ion diffusion, adsorption, chloride ion and chemical reaction of concrete components; Castro et al[5] established the chloride diffusion model of concrete with environmental factors such as temperature and humidity; Based on the finite difference method, the numerical calculation model of the influence of cement varieties, temperature and time on the distribution of chloride ion in concrete was established by Shi Yang-hang[6]; Xiao Jianzhuang[7] think of recycled concrete as multiphase materials composed of the natural aggregate, the old interface, the new interface, the old mortar and the new mortar, finite element software is adopted to establish the numerical model, simulate the two-dimensional diffusion process of chlorine ion. Based on the thermal analysis module of ANSYS, Zhao Xiangyu[8] set up a two-dimensional numerical simulation method to simulate the distribution of chloride ion. The numerical results are compared with the theoretical value of the two-dimensional diffusion equation of Fick second diffusion law, which indicates the correctness of the numerical simulation method.

In this paper, a numerical simulation method for the distribution of chloride ion concentration is established based on the similarity of the two dimensional heat conduction theory of Fourier law and the differential equation of the chloride ion diffusion theory in Fick law.

\section{Build A RANDOM Aggregate Model of Recycled CONCRETE}

Based on the understanding of the microstructure of recycled concrete, a random aggregate model of recycled concrete was established in ANSYS. As shown in Figure 1
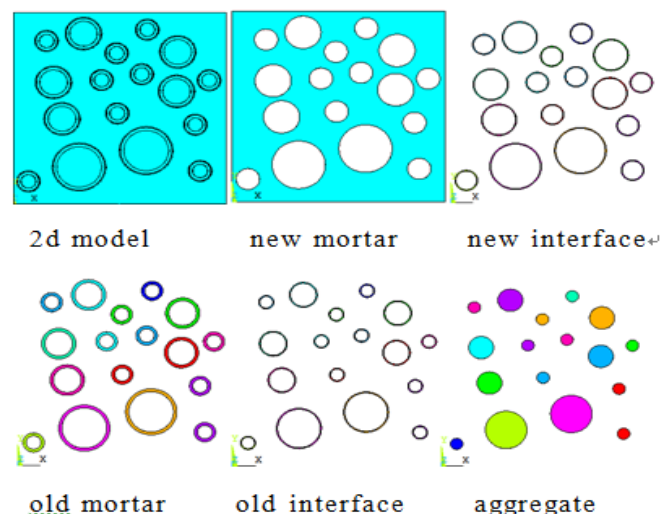

FIGURE I. 2D RANDOM AGGREGATE MODEL

It can be seen that the random aggregate model is composed of aggregate, old cement mortar, new cement mortar and the interface between the old mortar matrix and the new hardened cement mortar.

\section{CHLORINE ION DifFusion PROPERTIES OF EACH ELEMENT}

The $\mathrm{Cl}^{-}$diffusion performance of each element of recycled concrete is very different. According to the literature[7], The values of each parameter in the model are shown in Table 1. 
TABLE I. PARAMETER VALUE OF EACH ELEMENT $\left(10^{-6} \mathrm{MM}^{2} / \mathrm{S}\right)$

\begin{tabular}{|c|c|c|c|c|c|c|}
\hline $\begin{array}{c}\text { Material } \\
\text { composition }\end{array}$ & $\begin{array}{c}\text { Natural } \\
\text { aggregate }\end{array}$ & $\begin{array}{c}\text { Brick } \\
\text { aggregate }\end{array}$ & $\begin{array}{c}\text { Old } \\
\text { mortar }\end{array}$ & $\begin{array}{c}\text { New } \\
\text { mortal }\end{array}$ & $\begin{array}{c}\text { Old } \\
\text { face }\end{array}$ & $\begin{array}{c}\text { New } \\
\text { face }\end{array}$ \\
\hline $\begin{array}{c}\text { Diffusion } \\
\text { coeffcient }\end{array}$ & 0.2 & 500 & 23 & 5 & 360 & 74 \\
\hline
\end{tabular}

\section{FINITE ELEMENT MODEL}

\section{A. $\mathrm{Cl}^{-}$diffusion Equation Based on Fick Second Diffusion Law}

The $\mathrm{Cl}^{-}$diffusion equation of Fick second diffusion is assumed that the diffusion coefficient of chloride in concrete does not change with time and concentration, and the binding effect of gelled material on chloride ion is not considered. As shown in equation 1 :

$$
\frac{\partial C(x, y, t)}{\partial t}=D\left(\frac{\partial^{2} C(x, y, t)}{\partial x^{2}}+\frac{\partial^{2} C(x, y, t)}{\partial y^{2}}\right)
$$

In the equation, $\mathrm{C}(\mathrm{x}, \mathrm{y}, \mathrm{t})$ means the concentration of chloride at $(\mathrm{x}, \mathrm{y})$ at time $\mathrm{t}$; $\mathrm{D}$ means diffusion coefficient. The boundary conditions: Initial $\mathrm{Cl}^{-}$concentration in concrete is 0 , the $\mathrm{Cl}^{-}$concentration at the boundary is Cs, Eq(1) becomes:

$$
\begin{aligned}
& C(x, y, t)=C_{s}\left[1-\operatorname{erf}\left(\frac{x}{2 \sqrt{D t}}\right) \operatorname{erf}\left(\frac{y}{2 \sqrt{D t}}\right)\right] \\
& \frac{C(x, y, t)}{C_{s}}=1-\operatorname{erf}\left(\frac{x}{2 \sqrt{D t}}\right) \operatorname{erf}\left(\frac{y}{2 \sqrt{D t}}\right)
\end{aligned}
$$

\section{B. Model Parameter Setting}

By comparison, the PLANE55 element was used to simulate the diffusion of chloride ion in ANSYS. The chloride ion diffusion coefficient instead of heat transfer coefficient, the concentration boundary is one unit, density and specific heat capacity values of the parameters set to 1 , then simulate the temperature field distribution is almost as the distribution of chloride ion concentration. When the grid is partitioned, the element size is set to 6mm, The model consists of 22829 element and 12843 nodes. Its geometric model and finite element mesh are shown in Figure 2.
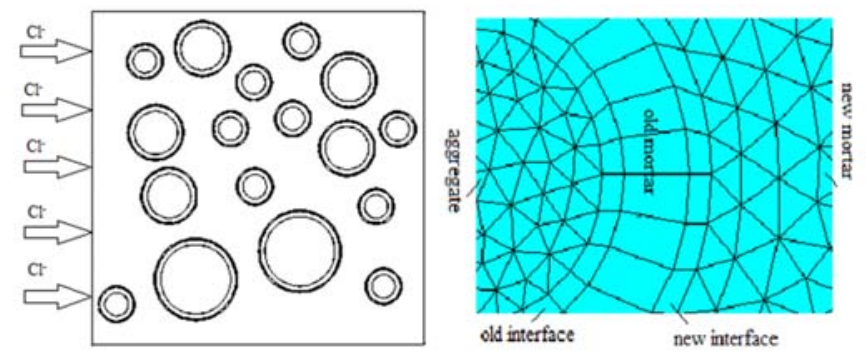

FIGURE II. GEOMETRIC MODEL AND FINITE ELEMENT MESH

\section{Validation of Model Validity}

In front of the chloride ion diffusion simulation, to prove that this method is feasible, in a simple example, the basic parameters for: component size is set to $100 \times 100 \mathrm{~mm}$, boundary of chlorine ion concentration is 0.6 , the initial concentration of chloride ion is 0 , concrete diffusion coefficient $\mathrm{D}$ is $1.8 \times 10^{-}$ ${ }^{6} \mathrm{~mm}^{2} / \mathrm{s}$.

First of all, the method presented in this paper is used for analysis, and quadrilateral element is used. Then, use equation (2) to carry out theoretical calculation. Finally, the theoretical calculation results are compared with the numerical simulation results to verify the validity of the simulation method.

The chloride concentration distribution of concrete cross sections in 5 and 10 years are extracted. Solve the prediction error and draw the error bar chart as shown in Figure 3.

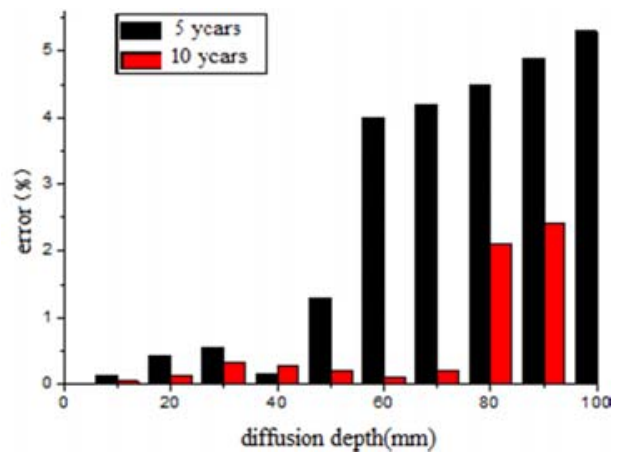

FIGURE III. THE ERROR BAR CHART

It can be seen, in the same time, as the diffusion depth increases, the chloride ion content becomes smaller. In the same diffusion depth, with the increase of time, the chloride ion content is increasing, which conforms to the law of chlorine ion diffusion. The obtained theoretical value curve is basically consistent with the result curve obtained by simulation. The maximum error is about 5\%, within the scope of the permit, the simulation method is feasible.

\section{CL ${ }^{-}$DIFFUSION ANALYSIS OF RECYCLED CONCRETE}

\section{A. The Diffusion Process}

With brick content was $0 \%$ of recycled concrete as an example of numerical calculation, get the relationship between the chloride ion concentration and depth. Firstly, the distribution value of chloride ion concentration along the $\mathrm{x}$ direction was extracted, and the diffusion coefficient of the five phases of recycled concrete was substituted into the second diffusion law for comparative analysis, The comparison between numerical results and theoretical values is shown in Figure 4.

It can be seen from the curve that chloride ion concentration is not evenly distributed, because the composition of the recycled concrete structure is random, which leads to the nonuniform velocity of chloride ion diffusion in concrete. In the diffusion process, with the increase of depth of diffusion, the chloride ion concentration drop like a wave, this is mainly due to the material properties of each phase is different, Because of the new mortar in internal accounting for the proportion of recycled concrete is bigger, the numerical curve is close to the theoretical curve of diffusion coefficient obtained using new mortar. 


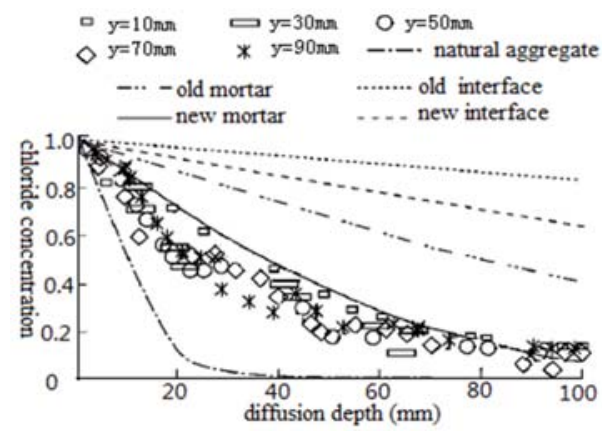

FIGURE IV. THE COMPARISON BETWEEN NUMERICAL RESULTS AND THEORETICAL VALUES

Then, the vector diagram of the change of chloride ion concentration of recycled concrete was extracted when the diffusion time $\mathrm{t}=10$ years, as shown in Figure 5 . The figure (a) shows that when faced with the natural aggregate, due to the chloride ion diffusion coefficient of natural aggregate smaller by a resistance, chloride ion will bypass is opposite the direction of the natural aggregate, flow along the mortar and the peripheral interface which permeability coefficient is larger, so the chloride ion concentration of natural aggregate will be much lower; As can be seen from figure (b), the concentration of chloride ion in the old interface is significantly higher than that of the old mortar, and the $\mathrm{cl}^{-}$is transmitted in a certain radian, rather than in a straight line; The above two points indicate that the natural aggregate and the interface change the direction and speed of chlorine ion transmission, and play a very important role in the $\mathrm{cl}^{-}$diffusion of recycled concrete.

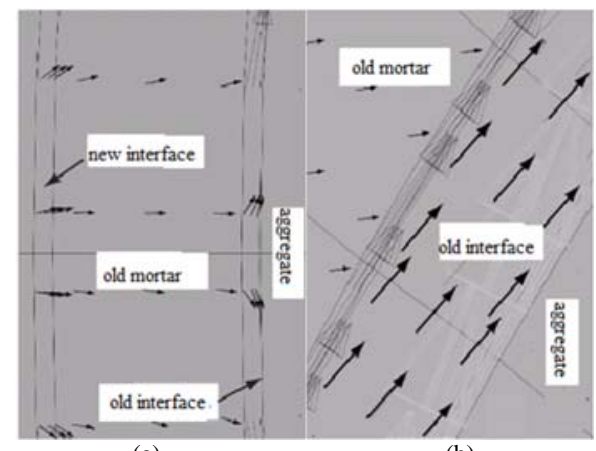

(a)

(b)

FIGURE V. VECTOR DETAIL DRAWING

\section{B. The Influence Factors of $\mathrm{Cl}^{-}$diffusion of Recycled Concrete}

The influencing factors of recycled concrete $\mathrm{Cl}^{-}$diffusivity can be divided into two kinds of factors, both internal and external, internal cause: internal composition of recycled concrete, concrete pore solution, internal cracks, concrete chloride ion binding ability and so on; External factors include: age, temperature and humidity, water cement ratio, admixture, etc. This section mainly discusses the effects of aggregate content and brick content on diffusion.

1) Aggregate content: The aggregate content of the specimens was analyzed by $0 \%, 20 \%, 30 \%, 40 \%$ and $50 \%$ respectively. When $t=10 y e a r s, \quad y=10,30,50,70,90 \mathrm{~mm}$, $\mathrm{x}=100 \mathrm{~mm}$, extract the concentration values and calculate the average value, draw the relationship curve between the content of recycled aggregate and chloride ion concentration, as shown in Figure 6.

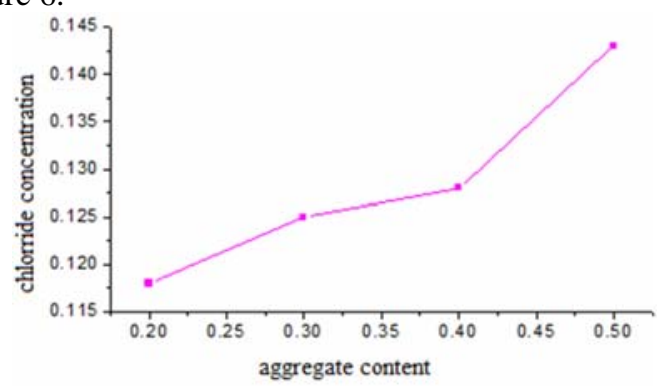

FIGURE VI. THE RELATIONSHIP BETWEEN AGGREGATE CONTENT AND CHLORIDE CONCENTRATION

The figure shows that with the increase of recycled coarse aggregate content, chloride ion concentration is increased, the reason is that recycled aggregates on the chloride ion diffusion resistance is reduced. With the increase of aggregate content, the number of the old interface with greater diffusion coefficient is increasing, and the diffusion channel is more and more. Although the increase of aggregate content can make the diffusion path more tortuous, the increase in the number of interfaces has a stronger effect on the diffusion than the aggregate barrier.

2) The content of bricks: The brick content of the specimens is $10 \%, 30 \%, 50 \%$ and $70 \%$ respectively. The distribution of bricks in the cross section is shown in Figure 7, where the red part represents the broken brick aggregate.

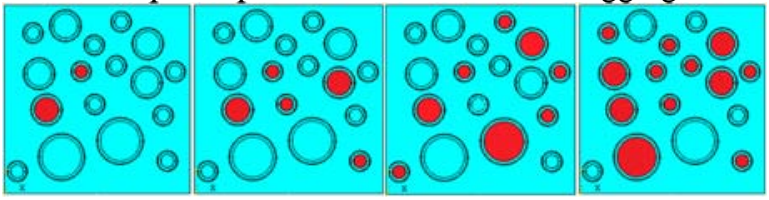

FIGURE VII. DIFFERENT BRICK CONTENT

By numerical calculation, the distribution of chloride ion concentration in the member section with depth is obtained. The distribution of chloride ion concentration along the $x$ direction was plotted in the case of $0 \%$ and $50 \%$ bricks when $t$ is 10 years and y is $50 \mathrm{~mm}$, as shown in Figure 8.

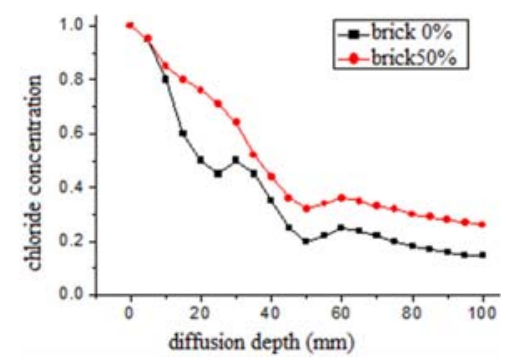

FIGURE VIII. THE DISTRIBUTION OF CHLORIDE ION CONCENTRATION ALONG THE X DIRECTION

It can be seen from that there is a difference in the concentration of chloride ion with depth when there are and without bricks. In the absence of bricks, with the increase of diffusion depth, due to natural aggregates, the diffusion process 
is blocked by natural aggregates, thus forming a wave shape at every aggregate. When brick content is $50 \%$ and y is $50 \mathrm{~mm}$, with the increase of depth, the first aggregate to meet is brick, provides the chloride ion diffusion channels, because the chloride ion diffusion coefficient of brick is larger. So the curve drops slowly at the first aggregate, and the second is in a wavy shape. Moreover, the curve of $50 \%$ brick is basically on the curve of $0 \%$ brick, which is the reason that natural aggregates prevent the diffusion of chloride ion.

Then, the chloride concentration of different bricks was extracted and averaged when $\mathrm{t}=10, \mathrm{x}=100 \mathrm{~mm}$, and $\mathrm{y}=10,30$, $50,70,90 \mathrm{~mm}$, and the relationship between chloride concentration and brick content was plotted as shown in figure 9.The distribution diagram of chloride ion concentration along the $\mathrm{x}$ direction was extracted when $\mathrm{y}=50 \mathrm{~mm}$, as shown in figure 10 .

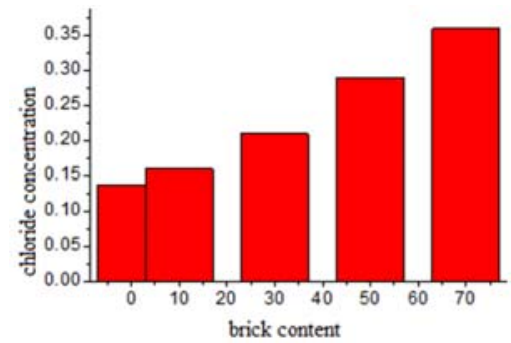

FIGURE IX. THE DETAILED DIAGRAM OF THE CHANGE VECTOR OF CHLORIDE ION CONCENTRATION

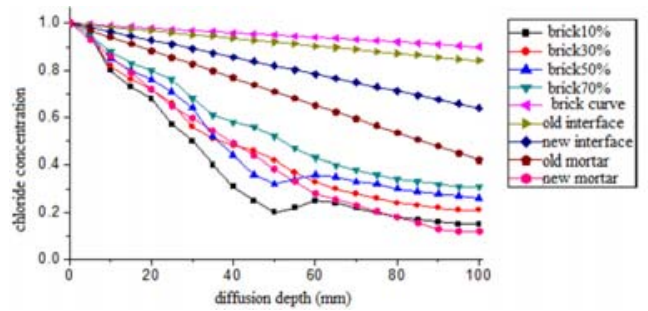

FIGURE X. THE RELATIONSHIP BETWEEN CHLORIDE CONCENTRATION AND BRICK CONTENT

As can be seen from figure 10, the distribution curve of chloride ion concentration with diffusion depth is within the theoretical range. With the increase of brick content, the numerical curve is far away from the theoretical curve of the diffusion coefficient of new mortar. This is mainly due to the increasing proportion of bricks in recycled concrete. It can be seen from the curve that, at the same depth, the chloride ion concentration increases with the increase of brick content, but only slightly changes in the aggregate of different properties (bricks and natural aggregates); The slope of the curve at the brick aggregate is slightly increased, and the curve is slowed down, indicating that the chlorine ion transport speed is faster than that of the brick aggregate.

\section{CONCLUSION}

On the basis of the microscopic model, the concentration distribution of chloride ion was simulated. The result shows that the diffusion coefficient of multiple components of recycled concrete is more complicated than that of the single regenerated concrete diffusion coefficient.
The concentration of chlorine ion in recycled concrete is unevenly distributed, and with the increase of diffusion depth, the concentration of chloride ion decreases in wave type. Then the influence of aggregate content and brick content on $\mathrm{Cl}^{-}$ diffusion is discussed. The diffusion law is as follows:

(1) With the increase of the content of recycled coarse aggregate, the concentration of chloride ion in recycled concrete increases.

(2) The influence of brick content on chloride ion diffusion is very significant. With the increase of brick content, chloride ion concentration increased. In other words, the permeability of recycled aggregate concrete is increasing and the durability is worse and worse. Therefore, in the production of recycled concrete, it is necessary to separate the discarded bricks to improve the durability of recycled concrete.

\section{ACKNOWLEDGMENT}

This work was financially supported by the Shandong Natural Science Foundation (ZR2014EL038). Ling-qiang Yang is responding author.

\section{REFERENCES}

[1] ZHANG Da-chang, XU En-xiang. Test study on impermeability of recycled concrete [J]. concrete, 2006,(11):36-38.

[2] JIN Wei-liang, ZHAO Yu-xi. DURABILITY OF CONCRETE STRUCTURES[M].Beijing: Science Press .2002.

[3] Maage M. Service life model for concrete structures exposed to marine environment initiation period[J]. ACI Material Journal, 1996, 93(6): 602-608.

[4] Chee Burm Shin, Eun KyumKim. Modeling of chloride ion ingress in coastal concrete [J]. PCI Journal, 2002(32)5:757-762.

[5] Castro P,De Rincon O T,Pazini E J. Interpretation of chloride profiles from concrete exposed to tropical marine environments[J]. Cement and Concrete Research, 2001,31(4):529-537.

[6] Shi Yanghang, Luo Gang.A FINITE DIFFERENCE CALCULATING MODEL OF CHLORIDE PENETRATING INTO CONCRETE UNDER VARIOUS FACTORS[J].Industrial building,2004,34(5):7-10.

[7] XIAO Jian-zhuang, YING Jingwei. Meso-level Numerical Simulation on Two-dimensional Chloride Diffusion in modeled Recycled Aggregate Concrete[J].Journal of Tongji University (NaturalScience), 2012,7, 40(7): 1051-1057.

[8] Zhao Xiangyu. Durability Study of Concrete Structures Basef on Chloride Ingress[D]. Chongqing University,2011.

[9] Cheng Weifeng.Research on Concrete Frame and Structure Model by numerical simulation[D]. Dalian University of Technology, 2008.

[10] Kwon S J, Na U J, Park SS, et al, Service life prediction of concrete wharves with early-age crack: probabilistic approach for chloride diffusion [J].Structural Safety, 2009,31(1):75.

[11] Care S. Influence of aggregates on chloride diffusion coefficient into mortar [J].Cement and Concrete Research,2003,33(7):1021. 